\title{
Diet and prey preference of juvenile lemon sharks Negaprion brevirostris
}

\author{
Steven P. Newman ${ }^{1,2, *}$, Richard D. Handy ${ }^{1}$, Samuel H. Gruber ${ }^{2,3}$ \\ ${ }^{1}$ School of Biological Sciences, University of Plymouth, Plymouth, Devon PL4 8AA, UK \\ ${ }^{2}$ Bimini Biological Field Station, Bimini, Bahamas \\ ${ }^{3}$ Rosenstiel School of Marine and Atmospheric Sciences, University of Miami, Miami 33149-1098, Florida, USA
}

\begin{abstract}
Sharks are often regarded as opportunistic asynchronous predators that feed on the most abundant prey. In the present study, 2 populations of juvenile lemon sharks Negaprion brevirostris were investigated from Bimini, Bahamas, with well-defined home ranges facilitating the estimation of prey preference. Stomach contents were quantitatively analysed from 396 lemon sharks with data on prey species and abundance obtained from quantitative sampling of mangrove and seagrass faunal communities to elucidate preferences with respect to prey type, prey size and location. Yellowfin mojarra Gerres cinereus dominated the diet of juvenile lemon sharks ( $>50 \%$ by weight and percentage index of relative importance, \%IRI), even when present in lower abundances in the environment. Preference was determined and compared using abundance, \%IRI values and original weight of prey, with the latter preferred due to their close relationship with energetic intake. Juvenile lemon sharks do not feed indiscriminately, but exhibit prey preference and size selection. Juvenile lemon sharks at Bimini demonstrated a hierarchy of prey preference: parrotfish (Scaridae) $>$ mojarra (Gerreidae) > toadfish (Batrachoididae) > filefish (Balistidae) $>$ grunts (Haemulidae) $>$ barracuda (Sphyraenidae). High overlap between shark diet and mangrove communities revealed the importance of mangroves to lemon sharks and their prey. Lemon sharks fed disproportionately on intermediate sized teleosts and crustaceans, with maximum prey size of nursery-bound sharks primarily limited by availability in the environment. We conclude that sharks can be highly plastic foragers, capable of selective feeding, but will switch to more opportunistic foraging when environmental conditions deteriorate.
\end{abstract}

KEY WORDS: Diet · Prey preference $\cdot$ Size selection $\cdot$ Predator-prey relationship $\cdot$ Foraging ecology Lemon shark Resale or republication not permitted without written consent of the publisher

\section{INTRODUCTION}

Sharks have a long-held reputation as opportunistic, asynchronous predators that feed on the most abundant prey (Springer 1960, Wetherbee et al. 1990). Dietary studies in sharks often compare prey composition with qualitative observations of prey communities; and these semi-quantitative reports of prey preference suggest sharks can be either opportunistic (e.g. Clarke 1971, Talent 1976, Schmidt 1986, Cortés \& Gruber 1990) or selective feeders (e.g. Tricas 1979, Stillwell \& Kohler 1982, Medved et al. 1985, Cortés et al. 1996). Prey preference has been quantified in a range of marine animals including teleosts (e.g. Lukoschek \& McCormick 2001), mammals (e.g. Wathne et al. 2000), birds (e.g. Lindberg et al. 1987), reptiles (e.g. LopezMendilaharsu et al. 2008) and invertebrates (e.g. Landenberger 1968). However, few studies have quantified prey preference in elasmobranchs, and subsequently there is a paucity of data for an entire vertebrate class.

Determining which prey are selected more often than others provides fundamental information on how predators meet their bioenergetic or ecological requirements for survival (Manley et al. 1993). Prey preference may play an important role in the growth 
and survival of a predator, and may in turn affect shark population fitness and adult recruitment (Feldheim et al. 2002). Subsequently, understanding the feeding behaviour of sharks is a necessary step in assessing their ecological requirements for habitat and prey species, ensuring their effective management and conservation (NMFS 2001).

Prey preference can be defined as the likelihood that a certain prey will be selected if offered on an equal basis with others (Johnson 1980). This is to be distinguished from prey selection, which is the process by which an animal chooses prey or characteristics of prey (Johnson 1980), such as selection of prey by size. The incidence of prey items in stomach contents and observations on feeding behaviour in the wild have indicated some degree of selective rather than random preferences in feeding behaviours of some sharks. White sharks Carcharodon carcharias may prefer seals at certain times (Tricas \& McCosker 1984), while tiger sharks Galeocerdo cuvier notably eat air-breathing marine vertebrates (e.g. Simpfendorfer et al. 2001, Heithaus et al. 2002). Some sharks appear to be very specialised feeders, for example the bonnethead shark Sphyrna tiburo feeds predominantly upon crabs (Bethea et al. 2007). To date, only 1 study has quantitatively described prey preference in a species of shark, with 2 selection indices used to reveal the preference of angel sharks Squatina dumeril for slower moving prey such as squid, scorpionfish and croakers (Baremore et al. 2008).

Estimates of quantitative prey preference can be logistically challenging because the measurements require simultaneous quantitative analysis of predator stomach contents and prey abundances in the ecosystem. The large home ranges possessed by many shark species make concurrent quantification of prey abundances and diet difficult. However, the juvenile lemon shark Negaprion brevirostris represents a good experimental model to resolve some of these problems. Juvenile lemon sharks utilise nursery areas for up to $5 \mathrm{yr}$, during which time they possess well-defined, small home ranges and demonstrate a high degree of site attachment and habitat selection, orientating to the mangrove fringe (Morrissey \& Gruber 1993a,b). This behaviour permits accurate simultaneous quantification and comparison of prey both in the diet and environment. The lemon shark belongs to the largest shark family, Carcharhinidae, which includes almost half of all extant sharks, and, as such, inferences may be made from the study of this species to many other species of sharks.

Lemon sharks are predominantly piscivorous, with crustaceans-mainly pink shrimp Penaeus duorarum and blue crabs Callinectes sp.--second in importance (Schmidt 1986, Cortés \& Gruber 1990). Cortés \& Gru- ber (1990) found the main teleost prey of juvenile lemon sharks at Bimini were snappers (Lutjanidae, $7.7 \%$ ) and porgies (Sparidae, 6\%), while porgies $(20 \%)$, mojarras (Gerreidae, $10 \%)$ and snappers $(8.5 \%)$ were the dominant prey in the Florida Keys (Cortés \& Gruber 1990). Small demersal fish, mainly toadfish Opsanus beta and pinfish Lagodon rhomboides, were the most common dietary items of juvenile lemon sharks in coastal marine waters in Florida (Schmidt 1986). Dietary studies of juvenile lemon sharks have suggested that the most prominent prey item in the diet was also the most abundant in the environment (Springer 1950, Schmidt 1986, Cortés \& Gruber 1990), although it has been hypothesized that lemon sharks may selectively feed on toadfish (Batrachoididae), due to their increased vulnerability while vocalising (Cortés \& Gruber 1990).

The overall aim of the present study was to quantitatively measure prey preference of lemon sharks in the wild, by concurrently sampling shark diet and available prey year-round in 2 nurseries with contrasting prey communities. The data were then used to address whether or not lemon sharks feed indiscriminately on available food, or exhibit a preference for certain prey species or size of prey. These comparisons provide insight into the optimal foraging of lemon sharks, and their ability to change prey preference or switch prey as circumstances in the ecosystem dictate.

\section{MATERIALS AND METHODS}

Dietary analysis. The diet of juvenile lemon sharks Negaprion brevirostris was quantified in 2 ecologically contrasting nurseries, North Sound and South Bimini, at Bimini, Bahamas $\left(25^{\circ} 44^{\prime} \mathrm{N}, 79^{\circ} 16^{\prime} \mathrm{W}\right)$. The North Sound is a highly enclosed euryhaline and eurythermal lagoon typified by dwarf mangroves and low prey biodiversity, while the South Bimini nursery is a stretch of coastline with dense fringing mangroves and a high prey abundance and diversity (Newman et al. 2007). Detailed descriptions of the hydrological, geochemical and ecological conditions at Bimini can be found elsewhere (Newell \& Imbrie 1955, Voss \& Voss 1960, Newman et al. 2007).

Six hundred and forty-two juvenile lemon sharks (total from both nurseries), ranging in precaudal length (PCL) from 43.5 to $90.0 \mathrm{~cm}$ (mean $\pm \mathrm{SE}, 54.7 \pm 0.3 \mathrm{~cm}$ ), were caught between March 2000 and March 2003 using monofilament gillnets $(180 \mathrm{~m}$ long, $2 \mathrm{~m}$ deep with a $5 \mathrm{~cm}$ square mesh) set perpendicular to shore extending from the mangrove fringe. Ethical approval and permissions were in place for all procedures. Upon capture, sharks were immediately removed from the net, sexed, weighed (to the nearest $0.01 \mathrm{~kg}$ ), measured 
(PCL, fork length [FL] and total length [TL], in $\mathrm{cm}$ ) and marked with a passive integrated transponder (PIT) tag (Destron Fearing), and the time as well as location were recorded. Stomach contents were collected using an established stomach eversion technique (Schurdak \& Gruber 1989). After lightly anaesthetising the shark in a 1:20 000 dilution of tricaine in seawater to facilitate safe handling of the animal, the stomach was gently everted using long forceps. Stomach contents were collected into $70 \%$ isopropyl alcohol, prior to sorting and analysis in the laboratory. The stomach was carefully returned to its original position, and sharks were held for $24 \mathrm{~h}$ in a field enclosure to ensure full recovery; then, they were fed and released. Of the sharks sampled for stomach contents, $69 \%$ were captured and sampled 3 or less times, with the mean $( \pm \mathrm{SE})$ time between sampling of $86.8 \pm 4.8 \mathrm{~d}$ (maximum of $771 \mathrm{~d}$, $\mathrm{n}=442$ ). Prey recovered from stomachs were identified to the lowest taxonomic level, counted, weighed and measured to the nearest millimetre (TL) when recovered intact. For most partially digested prey, recovered bones were measured and used to back-calculate the original total length and weight.

Sampling of prey communities. Prey communities were sampled concurrently with the sampling of shark stomach contents, using seine nets, trawls and gillnets. A detailed description of the techniques and communities sampled can be found in Newman et al. (2007). Locations of each sampling event were recorded using a WAAS GPS (Garmin, GPS 72), and the distance from shore was determined using a handheld laser rangefinder (DME Rangefinder, Laseroptronix AB). Prey sampling was confined to within $200 \mathrm{~m}$ from shore based on the work of Morrissey \& Gruber (1993a), which showed that juvenile lemon sharks are highly site-attached and remain close to the mangrove fringe where prey are mainly located (see Newman et al. 2007). All fish and macroinvertebrates collected were identified to species, measured (FL and TL in fish, carapace width [CW] in crabs and dorsal disc width in rays; all in $\mathrm{cm}$ ), weighed and released in situ.

Estimation of prey populations. Catch densities from mangrove and seagrass community sampling were interpolated over the study area to estimate prey population sizes in the environment. The study area was separated into mangrove and seagrass habitats, with seagrass further divided into 3 sectors ( 0 to 50, 50 to 100 and 100 to $200 \mathrm{~m}$ from the mangrove fringe) due to varying prey densities with distance from the mangrove fringe (see Newman et al. 2007). Mangrove depth from the fringe to the high tide mark was measured every $250 \mathrm{~m}$ along the coastline in each nursery. GPS points were taken in the field (Garmin WAAS GPS 72), and boundaries of these habitats and sectors were plotted on a georectified image of Bimini. GIS software (ESRI Arcview GIS 3.2) was used to accurately calculate the area of each habitat and sector due to the convoluted shoreline. Seine and trawl catches from each sector were then interpolated over the entire study area by converting net catches to densities (abundance and biomass per square meter) and multiplying by each sector area calculated in Arcview GIS. Population estimates from mangrove and seagrass habitats were then summed to provide an overall estimate of abundance and biomass of each prey family in the environment. Separate population estimates were calculated for the North Sound (NS) and South Bimini (SB) shark nurseries, as well as in the wet season (1 April to 30 September) and dry season (1 October to 31 March).

Data analysis. The dietary composition of the shark's stomach contents was analysed using the following indices (Pinkas et al. 1971, Hyslop 1980): percentage of each family present by number $(\% \mathrm{~N})$, wet weight $(\% \mathrm{~W})$, and frequency of occurrence $(\% \mathrm{O}$, the number of shark stomachs in which an item occurred). Compositions of net catches were similarly analysed, with \%O being percentage of the number of nets in which an item was found. For both catch and stomach contents, the index of relative importance (IRI), which incorporates all 3 indices was employed:

$$
\text { IRI }=\% \mathrm{O} \times(\% \mathrm{~N}+\% \mathrm{~W})
$$

To avoid pseudoreplication, percentage number and weight were calculated for each individual stomach and then averaged for each location/season, and, because $\% \mathrm{O}$ is a non-additive index, it was recalculated to each taxonomic level (Cortés 1997). The IRI was then expressed as a percentage (with $i$ as each individual shark stomach):

$$
\%_{\mathrm{IRI}_{i}}=100 \mathrm{IRI}_{i} / \sum_{i=1}^{n} \mathrm{IRI}_{i}
$$

Spatial and temporal variations in abundances of prey items in the diet of lemon sharks were analysed using contingency table analysis, with post hoc tests run individually eliminating variables to identify all sources of variability (Cortés 1997). To avoid small expected frequencies for $\chi^{2}$ tests, numbers of prey items were pooled into 13 categories: the 10 major prey families (Atherinidae, Batrachoididae, Belonidae, Gerreidae, Haemulidae, Lutjanidae, Penaeidae, Portunidae, Scaridae and Sphyraenidae), other teleosts, other crustaceans and miscellaneous prey items (elasmobranchs, polychaete worms and cephalopods). Nondietary items (e.g. sand, seagrass and inorganic material) were excluded from the analysis.

Diet breadth was calculated with Levin's standardised index ( $B_{\mathrm{A} i}$ Krebs 1999) and the Shannon-Wiener diversity index with evenness measure $\left(J^{\prime} ;\right.$ Krebs 1999$)$ 
using the 13 pooled categories and values of \%IRI. Each index was standardised on a scale of 0 to 1, with larger values indicating wider diet breadth. Two indices were used because Levin's gives more weight to the abundant resources used by a species, while Shannon-Wiener gives more weight to the rare resources (Krebs 1999).

Overlap in diets of lemon sharks from different locations or seasons were calculated using Spearman's rank correlation coefficient $\left(\mathrm{r}_{\mathrm{S}}\right)$, Horn's (1966) index of overlap $\left(R_{\mathrm{o}}\right)$ and the simplified Morisita index $\left(C_{\mathrm{H}}\right)$ (Krebs 1999). Diet was compared using \%IRI of all prey families as separate categories for the Spearman's rank and pooled into the same 13 categories used for analysis of dietary variation for Horn's and Morisita's index. The null hypothesis was that the diets of lemon sharks were different with location or season; therefore, if $r_{S}$ values were significant, the null hypothesis was rejected, indicating that the diets were similar. Values calculated by the simplified Morisita index range from 0 to 1 , with values $>0.60$ generally accepted as significant overlap (Zaret \& Rand 1971).

Overlap in the composition of lemon shark diet with prey communities specific to distance from shore sectors was assessed using Morisita's index and a null model generated by EcoSim v7 (Gotelli \& Entsminger 2009). Overlap was calculated by comparing \%IRI values for prey families in the diet of lemon sharks with prey communities from the mangroves and 3 seagrass sectors $(0$ to 50,50 to 100 and 100 to $200 \mathrm{~m}$ from the mangrove fringe) in each nursery. EcoSim was used to demonstrate statistical significance, using a randomization algorithm with niche breadth retained and zero states reshuffled using 1000 iterations, with the assumption that all prey resources were usable by lemon sharks.

Prey preference of juvenile lemon sharks was calculated using standardised chi-squared residuals to identify deviations between observed diets and abundance in the environment (Newman \& Waters 1984):

$$
\left(\text { Observed - Expected)/(Expected }{ }^{1 / 2}\right)
$$

Standardised and adjusted residuals provide a test of the significance of the electivity of a particular food type (Newman \& Waters 1984). Positive results indicate overrepresentation in the diet (prey selection), negative numbers indicate underrepresentation (prey avoidance) and zero values give an exact agreement between the relative amounts in the diet and the environment (frequency-dependent feeding). Chi-squared residuals have the advantage that they are a well-developed, nonparametric statistical test and are preferred because indices of electivity may overestimate the selection of rare items in the diet or the environment (see reviews by Cock 1978, Lechowicz 1982, Pearre 1982).
Diet and prey-abundance data were pooled into the 60 families identified around Bimini due to lack of identification to species level of some partially digested prey. Rays, bonefish, squid and sand eels were excluded from preference estimates due to probable scavenging behaviour or lack of targeted sampling for these prey communities (see 'Discussion'). Selection of prey size was estimated by comparing median prey sizes in the environment and in the diet of juvenile lemon sharks using Mann-Whitney $U$-tests.

\section{RESULTS}

\section{Stomach contents of lemon sharks}

Stomach contents were collected from 396 juvenile lemon sharks Negaprion brevirostris out of 642 caught (38\% empty stomachs), resulting in the identification of 719 dietary items. Fifty-two species were identified in the diet of juvenile lemon sharks at Bimini, with 37 species from 21 families of teleosts dominating the diet numerically, by biomass and in terms of their regular occurrence in stomach contents (Table 1). Juvenile lemon sharks consumed a wider range of prey in the North Sound (NS; 43 species from 25 families) than off South Bimini ( $\mathrm{SB}_{\text {; }} 31$ species from 26 families), although this may in part be a function of sample size. Despite consuming fewer species, lemon sharks from South Bimini had greater values of dietary breadth $\left(B_{\mathrm{A}}=0.13, J^{\prime}=0.51, \mathrm{n}=131\right)$ than in the North Sound $\left(B_{\mathrm{A}}=0.05, J^{\prime}=0.37, \mathrm{n}=265\right)$, although both were low, suggesting feeding specialisation. Sharks from the North Sound also averaged more dietary items in their stomachs (mean $\pm \mathrm{SE}$, NS: $1.92 \pm 0.11, \mathrm{n}=265$; SB: $1.78 \pm 0.12, \mathrm{n}=131$ ) and greater stomach content weight as a percent of body weight (BW) (mean $\pm \mathrm{SE}$, NS: $0.86 \pm 0.09 \%$ BW, $n=265$; SB: $0.82 \pm 0.14 \%$ BW, $\mathrm{n}=131$ ) than sharks off South Bimini, but neither were significant (Mann-Whitney $U$-tests, $\mathrm{p}=0.779$ and $\mathrm{p}=$ 0.613 , respectively).

Mojarra (Gerreidae) were the major prey of juvenile lemon sharks, contributing over half the weight of all prey ingested in both nurseries (Table 1). At the species level, $79 \%$ of all mojarra consumed (95\% by biomass) were yellowfin mojarra Gerres cinereus, with the remainder from the genus Eucinostomus. Parrotfish (Scaridae), barracuda (Sphyraenidae) and grunts (Haemulidae) were the other major teleost prey of lemon sharks at Bimini. Combined with mojarra, these prey families comprised 71 and $77 \%$ of the biomass of prey consumed by juvenile lemon sharks in the North Sound and South Bimini nurseries, respectively. Crustacean prey, predominantly swimming crabs (Portunidae) and penaeid shrimps (Penaeidae), were second 
in importance to teleosts (Table 1). Crustaceans were more important in the diet of lemon sharks from the North Sound than off South Bimini, contributing 6.60\% IRI of the diet in comparison to only $0.86 \%$ IRI (Table 1). Elasmobranchs, cephalopods and annelids formed an insignificant part of the diet of nurserybound juvenile lemon sharks (Table 1). While unidentified teleosts comprised around 10\% IRI, they accounted for $<1.5 \%$ of the mass of ingested lemon shark prey in both nurseries (Table 1).

Contingency-table analysis revealed a significant difference in dietary composition with location $\chi^{2}=$ 62.33, 12 df, $\mathrm{p}<0.0001$; using pooled samples). Despite this difference in dietary composition, there was still a significant degree of overlap in prey species consumed $\left(\mathrm{r}_{\mathrm{S}}=0.62, \mathrm{p}<0.001 ; R_{\mathrm{o}}=0.89 ; C_{\mathrm{H}}=0.94\right)$. Post hoc analysis revealed lemon sharks from the North Sound consumed proportionally more mojarra, swimming crabs, penaeid shrimp and other teleosts, whilst lemon sharks off South Bimini consumed proportionally more parrotfish (Table 1). When these prey categories were removed, there was no significant difference in lemon shark dietary composition between the 2 nurseries $\left(\chi^{2}=8.15,8 \mathrm{df}, \mathrm{p}=0.419\right)$.

The difference in dietary composition of lemon sharks from North Sound and South Bimini nurseries

Table 1. Negaprion brevirostris. Dietary composition in the North Sound and South Bimini, Bahamas. Percentage number (\%N), occurrence $(\% \mathrm{O})$ and weight $(\% \mathrm{~W})$ were calculated from the cumulative number $(\mathrm{N})$, occurrence $(\mathrm{O}$, number of stomachs in which an item was found) and weight ( $\mathrm{W}$, in $\mathrm{g}$ ) and were used to calculate the index of relative importance expressed as a percentage (\%IRI). Occurrence values are non-additive and were therefore recalculated for each taxonomic level. Sample size (number of lemon shark stomachs examined) is provided in parentheses. -: item not found in the samples

\begin{tabular}{|c|c|c|c|c|c|c|c|c|c|c|c|c|c|c|}
\hline \multirow[t]{2}{*}{ Dietary item } & \multirow{2}{*}{$\mathrm{N}$} & \multirow{2}{*}{$\mathrm{O}$} & \multicolumn{5}{|c|}{-North Sound $(\mathrm{n}=265)$} & \multirow[b]{2}{*}{$\mathrm{N}$} & \multirow{2}{*}{$\mathrm{O}$} & \multicolumn{5}{|c|}{ - South Bimini $(n=131)$} \\
\hline & & & W & $\% \mathrm{~N}$ & $\% O$ & $\% W$ & $\%$ IRI & & & W & $\% \mathrm{~N}$ & $\% \mathrm{O}$ & $\% \mathrm{~W}$ & $\%$ IRI \\
\hline Teleostei & 380 & 219 & 3418.15 & 77.3 & 82.6 & 82.46 & 93.30 & 203 & 122 & 2258.54 & 89.8 & 93.1 & 97.54 & 99.13 \\
\hline Albulidae (bonefishes) & - & - & - & - & - & - & - & 2 & 2 & 215.27 & 0.9 & 1.5 & 9.30 & 0.41 \\
\hline Atherinidae (silversides) & 27 & 15 & 44.17 & 5.5 & 5.7 & 1.05 & 0.86 & 15 & 13 & 15.49 & 6.6 & 9.9 & 0.67 & 1.90 \\
\hline Balistidae (triggerfish \& filefishes) & 16 & 5 & 20.02 & 3.2 & 1.9 & 0.48 & 0.16 & 1 & 1 & 11.45 & 0.4 & 0.8 & 0.49 & 0.02 \\
\hline Batrachoididae (toadfish) & 10 & 9 & 41.17 & 2.0 & 3.4 & 0.98 & 0.24 & 10 & 9 & 12.22 & 4.4 & 6.9 & 0.53 & 0.89 \\
\hline Belonidae (needlefishes) & 8 & 7 & 41.85 & 1.6 & 2.6 & 1.00 & 0.16 & 3 & 3 & 68.73 & 1.3 & 2.3 & 2.97 & 0.26 \\
\hline Bothidae (lefteye flounders) & 1 & 1 & 0.15 & 0.2 & 0.4 & 0.00 & $<0.01$ & - & - & - & - & - & - & - \\
\hline Carangidae (jacks) & 5 & 5 & 30.57 & 1.0 & 1.9 & 0.73 & 0.08 & 2 & 2 & 4.06 & 0.9 & 1.5 & 0.18 & 0.04 \\
\hline Cyprinodontidae (killifishes) & 4 & 3 & 1.06 & 0.8 & 1.1 & 0.03 & 0.02 & - & - & - & - & - & - & - \\
\hline Gerreidae (mojarras) & 120 & 104 & 2169.38 & 24.3 & 39.2 & 51.74 & 69.39 & 43 & 37 & 1323.58 & 19.0 & 28.2 & 57.16 & 56.35 \\
\hline Gobiidae (gobies) & 5 & 5 & 13.81 & 1.0 & 1.9 & 0.33 & 0.06 & 1 & 1 & 0.05 & 0.4 & 0.8 & 0.00 & 0.01 \\
\hline Haemulidae (grunts) & 13 & 12 & 159.11 & 2.6 & 4.5 & 3.79 & 0.67 & 11 & 11 & 158.14 & 4.9 & 8.4 & 6.83 & 2.57 \\
\hline Hemiramphidae (halfbeaks) & 2 & 2 & 9.87 & 0.4 & 0.8 & 0.24 & 0.01 & - & - & - & - & - & - & - \\
\hline Labridae (wrasses) & 2 & 2 & 2.25 & 0.4 & 0.8 & 0.05 & 0.01 & 1 & 1 & 18.59 & 0.4 & 0.8 & 0.80 & 0.03 \\
\hline Lutjanidae (snappers) & 15 & 14 & 135.26 & 3.0 & 5.3 & 3.23 & 0.77 & 10 & 9 & 71.44 & 4.4 & 6.9 & 3.09 & 1.35 \\
\hline Ophichthidae (snake eels) & 5 & 5 & 5.57 & 1.0 & 1.9 & 0.13 & 0.05 & 1 & 1 & 0.92 & 0.4 & 0.8 & 0.04 & 0.01 \\
\hline Pomacentridae (damselfishes) & - & - & - & - & - & - & - & 2 & 2 & 16.96 & 0.9 & 1.5 & 0.73 & 0.07 \\
\hline Scaridae (parrotfishes) & 35 & 27 & 180.21 & 7.1 & 10.2 & 4.30 & 2.70 & 50 & 32 & 217.50 & 22.1 & 24.4 & 9.39 & 20.16 \\
\hline Soleidae (soles) & - & - & - & - & - & - & - & 1 & 1 & 0.49 & 0.4 & 0.8 & 0.02 & 0.01 \\
\hline Sparidae (porgies) & 1 & 1 & 0.38 & 0.2 & 0.4 & 0.01 & $<0.01$ & 1 & 1 & 0.33 & 0.4 & 0.8 & 0.01 & 0.01 \\
\hline Sphyraenidae (barracuda) & 27 & 26 & 469.02 & 5.5 & 9.8 & 11.19 & 3.80 & 10 & 10 & 93.67 & 4.4 & 7.6 & 4.05 & 1.69 \\
\hline Synodontidae (lizardfishes) & 1 & 1 & 40.91 & 0.2 & 0.4 & 0.98 & 0.01 & - & - & - & - & - & - & - \\
\hline Unidentified teleosts & 83 & 65 & 53.39 & 16.8 & 24.5 & 1.27 & 10.27 & 39 & 36 & 29.65 & 17.3 & 27.5 & 1.28 & 13.34 \\
\hline Elasmobranchii & 3 & 3 & 505.67 & 0.6 & 1.1 & 12.06 & 0.10 & - & - & - & - & - & - & 0.00 \\
\hline Dasyatidae (whiptail stingrays) & 3 & 3 & 505.67 & 0.6 & 1.1 & 12.06 & 0.33 & - & - & - & - & - & - & - \\
\hline Crustacea & 108 & 90 & 225.02 & 22.1 & 34.0 & 5.41 & 6.60 & 20 & 18 & 48.55 & 8.8 & 13.7 & 2.10 & 0.86 \\
\hline Alphaeidae (snapping shrimps) & - & - & - & - & - & - & - & 1 & 1 & 1.09 & 0.4 & 0.8 & 0.05 & 0.01 \\
\hline Gonodactylidae (mantis shrimps) & 3 & 3 & 1.80 & 0.6 & 1.1 & 0.04 & 0.02 & 2 & 2 & 0.44 & 0.9 & 1.5 & 0.02 & 0.04 \\
\hline Panurilidae (lobsters) & - & - & - & - & - & - & - & 1 & 1 & 1.08 & 0.4 & 0.8 & 0.05 & 0.01 \\
\hline Penaeidae (shrimps) & 41 & 32 & 32.09 & 8.3 & 12.1 & 0.77 & 2.55 & 6 & 4 & 7.50 & 2.7 & 3.1 & 0.32 & 0.24 \\
\hline Portunidae (swimming crabs) & 57 & 56 & 179.92 & 11.5 & 21.1 & 4.29 & 7.76 & 6 & 6 & 25.09 & 2.7 & 4.6 & 1.08 & 0.45 \\
\hline Pseudosquillidae (mantis shrimps) & 6 & 6 & 11.20 & 1.2 & 2.3 & 0.27 & 0.08 & 2 & 2 & 1.76 & 0.9 & 1.5 & 0.08 & 0.04 \\
\hline Xanthidae (mud crabs) & 1 & 1 & 0.01 & 0.2 & 0.4 & 0.00 & $<0.01$ & 2 & 2 & 11.59 & 0.9 & 1.5 & 0.50 & 0.06 \\
\hline Mollusca & - & - & - & - & - & - & 0.00 & 1 & 1 & 0.06 & 0.4 & 0.8 & 0.00 & $<0.01$ \\
\hline Loliginidae (inshore squid) & - & - & - & - & - & - & - & 1 & 1 & 0.06 & 0.4 & 0.8 & 0.00 & 0.01 \\
\hline Annelida & 1 & 1 & 2.94 & 0.2 & 0.4 & 0.07 & $<0.01$ & 2 & 2 & 8.37 & 0.9 & 1.5 & 0.36 & 0.01 \\
\hline Arenicolidae (lugworms) & 1 & 1 & 2.94 & 0.2 & 0.4 & 0.07 & $<0.01$ & 2 & 2 & 8.37 & 0.9 & 1.5 & 0.36 & 0.05 \\
\hline
\end{tabular}


was significant in both the wet $\left(\chi^{2}=32.27,12 \mathrm{df}, \mathrm{p}=\right.$ $0.001)$ and dry season $\left(\chi^{2}=42.77,12 \mathrm{df}, \mathrm{p}<0.001\right.$; see Table 2). Mojarra were the main prey of lemon sharks in both nurseries regardless of season, with parrotfish a major component of the diet of lemon sharks from South Bimini, and crustaceans more important in the diet of lemon sharks from the North Sound (Table 2). Barracuda and swimming crabs were more important in the diet of lemon sharks during the dry season in both nurseries. However, despite minor variations in the importance of different prey in the diet of juvenile lemon sharks, no significant seasonal variation in dietary composition was observed within each nursery
$\left(\mathrm{SB}: \chi^{2}=19.94,12 \mathrm{df}, \mathrm{p}=0.070 ; \mathrm{NS}: \chi^{2}=9.31,12 \mathrm{df}, \mathrm{p}=\right.$ $0.676)$. Lemon shark diet was homogeneous with respect to gender $\left(\chi^{2}=13.21,12 \mathrm{df}, \mathrm{p}=0.354\right)$, with a high degree of dietary overlap $\left(\mathrm{r}_{\mathrm{S}}=0.86, \mathrm{p}<0.001 ; R_{\mathrm{o}}=\right.$ $\left.0.98 ; C_{\mathrm{H}}=0.99\right)$ and similar measures of diet breadth in males $\left(B_{\mathrm{A}}=0.08, J^{\prime}=0.43 ; \mathrm{n}=188\right)$ to females $\left(B_{\mathrm{A}}=\right.$ $\left.0.07, J^{\prime}=0.43 ; \mathrm{n}=184\right)$.

\section{Estimates of prey populations}

Mojarra, silversides, penaeid shrimp, swimming crabs and needlefish were the most abundant prey in

Table 2. Negaprion brevirostris. Seasonal variation in diet (expressed as percentage index of relative importance) and prey population abundance $(\mathrm{N})$ and biomass $(\mathrm{W}$, in $\mathrm{kg}$ ) estimates from the North Sound and South Bimini, Bahamas. Sample size (number of lemon shark stomachs examined) is provided in parentheses. -: prey family not found

\begin{tabular}{|c|c|c|c|c|c|c|c|c|c|c|c|c|}
\hline & \multicolumn{6}{|c|}{ - North Sound - } & \multicolumn{6}{|c|}{-South Bimini - } \\
\hline & \multicolumn{3}{|c|}{ Dry season } & \multicolumn{3}{|c|}{ Wet season } & \multicolumn{3}{|c|}{ Dry season } & \multicolumn{3}{|c|}{ Wet season } \\
\hline & $\mathrm{N}$ & $\mathrm{W}$ & $\begin{array}{c}\text { Diet } \\
(131)\end{array}$ & $\mathrm{N}$ & W & $\begin{array}{l}\text { Diet } \\
(134)\end{array}$ & $\mathrm{N}$ & W & $\begin{array}{l}\text { Diet } \\
(72)\end{array}$ & $\mathrm{N}$ & W & $\begin{array}{l}\text { Diet } \\
\text { (59) }\end{array}$ \\
\hline \multicolumn{13}{|l|}{ Teleosts } \\
\hline Albulidae (bonefishes) & 68 & 105.16 & - & 583 & 572.33 & - & 92 & 60.10 & 1.49 & 23 & 22.62 & - \\
\hline Atherinidae (silversides) & 19282 & 48.95 & 0.30 & 519608 & 1574.83 & 1.63 & 452732 & 326.64 & 1.02 & 139894 & 4379.09 & 3.39 \\
\hline Balistidae (triggerfish \& filefishes) & 800 & 1.92 & - & 81 & 1.28 & 0.68 & 2498 & 4.73 & 0.06 & 1209 & 5.55 & - \\
\hline Batrachoididae (toadfish) & 419 & 1.99 & 0.30 & - & - & 0.13 & 882 & 5.81 & 0.70 & 81 & 0.36 & 1.11 \\
\hline Belonidae (needlefishes) & 25312 & 483.09 & 0.14 & 11279 & 143.74 & 0.17 & 12516 & 451.05 & 0.32 & 12098 & 305.70 & 0.17 \\
\hline Bothidae (lefteye flounders) & 955 & 1.07 & - & 31 & 0.04 & 0.01 & 939 & 1.24 & - & 1513 & 19.18 & - \\
\hline Carangidae (Jacks) & 261 & 1.05 & 0.01 & 630 & 3.02 & 0.22 & 266 & 148.12 & 0.13 & 335 & 35.91 & - \\
\hline Cyprinodontidae (killifishes) & 7508 & 2.87 & 0.08 & 3838 & 2.15 & - & - & - & - & - & - & - \\
\hline Gerreidae (mojarras) & 149041 & 1040.04 & 63.95 & 294611 & 2070.93 & 72.32 & 26690 & 918.86 & 58.47 & 58306 & 584.05 & 45.21 \\
\hline Gobiidae (gobies) & 619 & 1.73 & 0.22 & 122 & 0.41 & - & 16895 & 18.38 & 0.03 & 15439 & 23.15 & - \\
\hline Haemulidae (grunts) & 773 & 5.53 & 0.63 & 2830 & 44.94 & 0.70 & 31030 & 377.24 & 5.40 & 34003 & 372.20 & 0.50 \\
\hline Hemiramphidae (halfbeaks) & 2437 & 14.01 & 0.01 & 7438 & 25.71 & 0.01 & 14753 & 54.96 & - & 2298 & 94.18 & - \\
\hline Labridae (wrasses) & 380 & 0.82 & 0.03 & 97 & 1.15 & - & 4890 & 13.87 & - & 3416 & 13.98 & - \\
\hline Lutjanidae (snappers) & 4349 & 40.86 & 0.68 & 5271 & 139.22 & 0.92 & 11027 & 754.93 & 0.48 & 17446 & 224.03 & 3.07 \\
\hline Ophichthidae (snake eels) & - & - & 0.03 & - & - & 0.08 & 117 & 0.56 & 0.03 & 151 & 0.72 & - \\
\hline Pomacentridae (damselfishes) & - & - & - & - & - & - & 3005 & 10.81 & 0.21 & 2232 & 12.82 & - \\
\hline Scaridae (parrotfishes) & 3502 & 32.99 & 2.65 & 6463 & 28.96 & 2.58 & 53292 & 272.17 & 22.89 & 65610 & 391.89 & 14.78 \\
\hline Soleidae (soles) & 4271 & 10.93 & - & 5359 & 19.85 & - & 87 & 0.01 & - & 46 & 0.44 & 0.05 \\
\hline Sparidae (porgies) & 211 & 5.91 & 0.01 & 378 & 14.58 & - & 290 & 62.39 & 0.03 & 1180 & 103.03 & - \\
\hline Sphyraenidae (barracuda) & 4857 & 330.51 & 5.89 & 3640 & 251.39 & 2.03 & 5190 & 391.43 & 2.49 & 4183 & 293.70 & 0.85 \\
\hline Synodontidae (lizardfishes) & 98 & 1.95 & 0.04 & 142 & 7.78 & - & 222 & 5.08 & - & 23 & 0.14 & - \\
\hline Unidentified teleosts & - & - & 9.69 & - & - & 10.53 & - & - & 5.04 & - & - & 30.26 \\
\hline \multicolumn{13}{|l|}{ Crustaceans } \\
\hline Alphaeidae (snapping shrimps) & 19 & 0.02 & - & - & - & - & 2890 & 4.74 & 0.03 & 1838 & 1.92 & - \\
\hline Gonodactylidae (mantis shrimps) & 236 & 0.78 & - & - & - & 0.07 & 130 & 0.02 & 0.03 & 442 & 0.88 & 0.05 \\
\hline Ocypodidae (fiddler crabs) & - & - & 0.01 & 85 & 0.01 & - & 29 & 0.01 & - & - & - & - \\
\hline Palinuridae (lobsters) & 17 & 0.00 & - & 31 & 0.02 & - & 238 & 15.88 & - & 92 & 0.01 & 0.05 \\
\hline Penaeidae (shrimps) & 64696 & 24.11 & 1.78 & 44750 & 28.54 & 3.23 & 4026 & 3.05 & 0.42 & 8917 & 6.43 & 0.06 \\
\hline Portunidae (swimming crabs) & 48295 & 233.15 & 13.39 & 62604 & 146.11 & 3.32 & 6895 & 104.88 & 0.55 & 6331 & 85.40 & 0.29 \\
\hline Pseudosquillidae (mantis shrimps) & 1002 & 1.26 & 0.12 & 731 & 0.92 & 0.04 & 2172 & 3.63 & 0.03 & 2912 & 6.97 & 0.05 \\
\hline Xanthidae (mud crabs) & 7726 & 7.88 & - & 8450 & 14.40 & 0.01 & 3776 & 5.40 & 0.17 & 7211 & 18.68 & - \\
\hline \multicolumn{13}{|l|}{ Elasmobranchs } \\
\hline Dasyatidae (whip-tail stingrays) & - & - & - & 31 & 8.61 & 1.32 & 301 & 4797.15 & - & 81 & 1841.46 & - \\
\hline \multicolumn{13}{|l|}{ Cephalopods } \\
\hline Loliginidae (inshore squid) & 62 & 0.51 & - & - & - & - & - & - & - & - & - & 0.05 \\
\hline \multicolumn{13}{|l|}{ Annelids } \\
\hline Arenicolidae (lugworms) & - & - & - & - & - & - & - & - & - & - & - & 0.05 \\
\hline
\end{tabular}


the North Sound (Table 2). In contrast, prey communities in the environment off South Bimini had larger populations of grunts, snappers and parrotfish, as well as abundant silversides, needlefish and mojarra. Yellowfin mojarra accounted for $6 \%$ of all mojarra caught in the North Sound and $12 \%$ of mojarra catches off South Bimini by abundance. Despite their relatively low abundance, barracuda formed a large proportion of the prey community biomass in both nurseries. Mojarra, parrotfish and silversides were more abundant in the wet season in both nurseries (Table 2). Despite extensive sampling with multiple gear types, burrowing organisms such as snake eels (Ophichthidae) were undersampled.

\section{Prey preference of lemon sharks}

Juvenile lemon sharks demonstrated preferential feeding by only preying upon 49 out of 175 species $(28 \%)$ of fish and macroinvertebrates identified at Bimini, Bahamas. Lemon sharks at Bimini exhibited preferential feeding, with proportions of prey families in the diet significantly different from those found in the environment in both the North Sound $\left(\chi^{2}=\right.$ 10809.80, 22 df, $\mathrm{p}<0.001)$ and South Bimini shark nurseries $\left(\chi^{2}=6828.57,22 \mathrm{df}, \mathrm{p}<0.001\right)$. The most preferred prey of juvenile lemon sharks were toadfish, parrotfish and barracuda in both nurseries (Fig. 1A). Lemon sharks also demonstrated a preference in both nurseries for jacks, mantis shrimps (Gonodactylidae), snappers, grunts, penaeid shrimps and swimming crabs (Fig. 1A).

Mojarra, the major prey of juvenile lemon sharks (see Table 1), were preyed upon almost opportunistically by lemon sharks in the North Sound (Fig. 1A). However, when present in lower numbers off South Bimini (see Table 2), the preference that lemon sharks exhibit for their main prey was evident (Fig. 1A). Similarly, lemon sharks demonstrated a high preference for filefish (Balistidae; Fig. 1A) in the North Sound when present in lower abundances in the environment (see Table 2). Parrotfish were another major prey of juvenile lemon sharks, and they were highly preferred even when in high abundance off South Bimini (see Fig. 1, Table 2). Silversides (Atherinidae) were the least preferred prey of juvenile lemon sharks with chisquared values of -12.5 and -7.1 for sharks from the North Sound and South Bimini nurseries, respectively (Fig. 1A).

Lemon sharks fed selectively year-round, although greatest preference was exhibited during the wet season $\left(\chi^{2}=42902.27,54 \mathrm{df}, \mathrm{p}<0.0001\right)$ rather than the dry season $\left(\chi^{2}=1275.28,61 \mathrm{df}, \mathrm{p}<0.0001\right)$. Toadfish were selectively preyed upon year-round, but were highly preferred during the wet season in both nurseries, with chi-squared residuals exceeding 130 in both nurseries in comparison to 10 during the dry season.

\section{Prey preference using original prey weight}

Original weight could be estimated for 260 of the 492 prey items ingested by lemon sharks in the North Sound (53\%) and for 140 of the 226 prey consumed off South Bimini (62\%; Table 3). Estimates of original prey weights resulted in an increase in the biomass of most prey families identified in the diet of lemon sharks at Bimini, despite the smaller sample size (see Tables 1 \& 3). Original parrotfish biomass was 5 and 6 times the digested weight recovered from lemon shark stomachs in the North Sound and off South Bimini, respectively (Table 3). Parrotfish, mojarra and toadfish were the most preferred prey of lemon sharks in both nurseries (Fig. 1B). Chi-squared residuals calculated using original prey weights revealed increased preference for parrotfish, mojarra and filefish, while preference for toadfish, sole (Soleidae) and porgies (Sparidae) declined (Fig. 1B). Silversides and needlefish remained the least preferred prey in the diet of lemon sharks.

\section{Prey preference using \%IRI}

Prey preference determination using the \%IRI values provides a clearer picture of the degree of preference exhibited by juvenile lemon sharks for mojarra, parrotfish and toadfish (Fig. 1C). Silversides and needlefish were the least preferred prey of lemon sharks in both nurseries (Fig. 1C). Using \%IRI values, most crustaceans were preyed upon almost opportunistically by lemon sharks. The high importance of crustaceans in the diet of North Sound lemon sharks is an underrepresentation of their \%IRI in the environment, and as such they demonstrate negative values of preference (Fig. 1C). Similarly, lemon sharks off South Bimini show a lower preference for gobies, grunts, snappers and barracuda.

\section{Diet and community overlap}

High values of overlap calculated using Morisita's index indicated a strong relationship between shark diet and prey communities, supported by observed mean overlap being statistically greater than the null model for each location and season ( $p>0.001)$, although observed variance was not statistically different from the null model except off South Bimini in the wet season where it was significantly greater $(p=0.04)$. Diet of the 
lemon shark demonstrated a greater degree of overlap with prey communities in the North Sound than off South Bimini, probably due to the high abundance of mojarra throughout the North Sound. Values of overlap between prey in the diet of juvenile lemon sharks and the environment were greater for mangrove communities and typically decreased with increasing distance from shore (Fig. 2). Greater overlap between shark diet
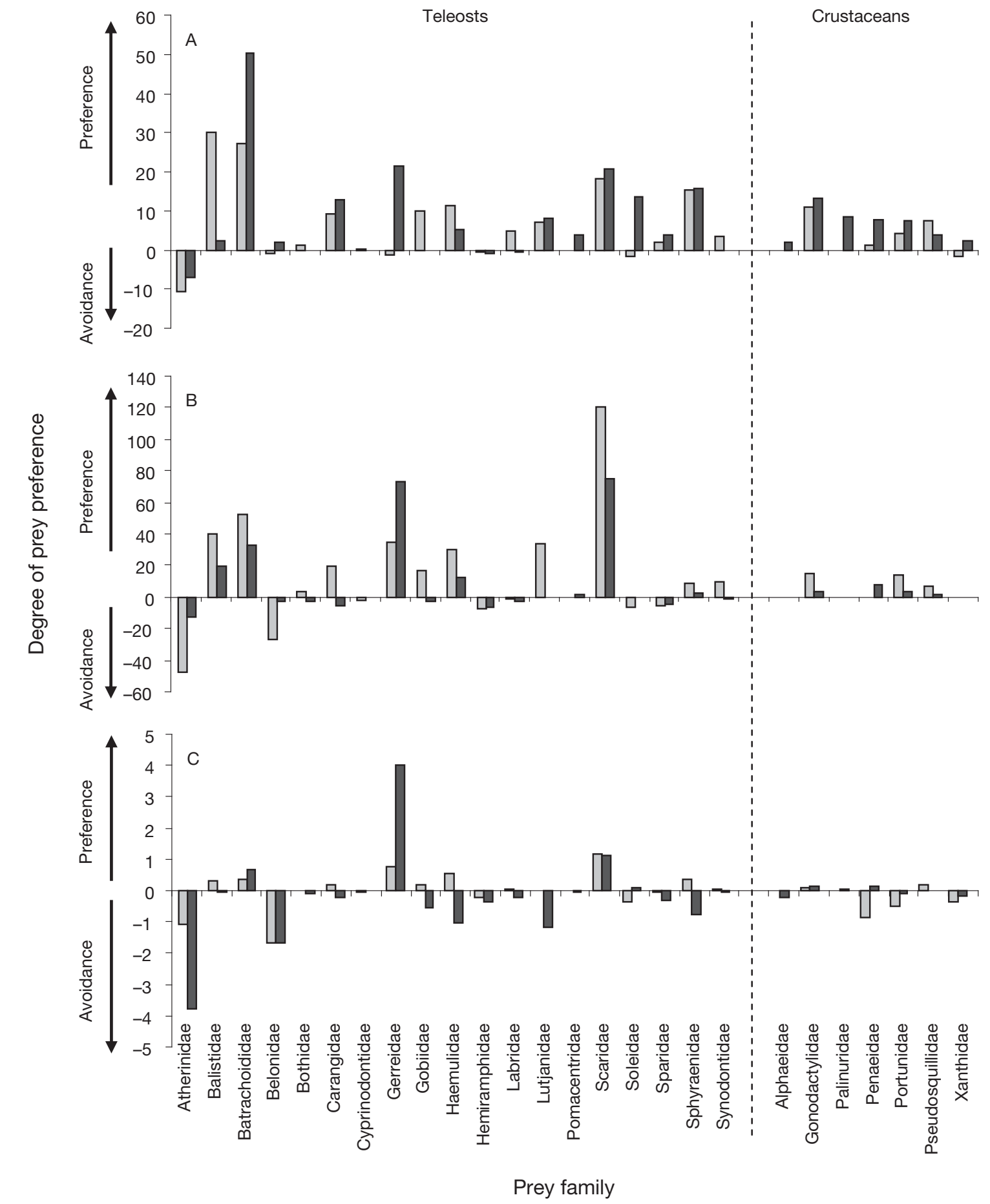

Crustaceans

Fig. 1. Negaprion brevirostris. Prey preference in the North Sound $(\square, \mathrm{n}=265)$ and South Bimini $(\square, \mathrm{n}=131)$, determined by standardised $\chi^{2}$ residuals [(Observed - Expected)/(Expected $\left.)^{1 / 2}\right]$. Preference was calculated using abundance (A), original weight of prey items consumed (B) and percentage index of relative importance (C). Positive residuals indicate overrepresentation in the diet (selection), negative numbers underrepresentation (avoidance). $\chi^{2}$ values were significant in both shark nurseries: North Sound $\left(\chi^{2}=10809.80,22 \mathrm{df}, \mathrm{p}<0.001\right)$ and South Bimini $\left(\chi^{2}=6828.57,22 \mathrm{df}, \mathrm{p}<0.001\right)$ 
Table 3. Negaprion brevirostris. Original weight of prey consumed by juvenile lemon sharks, calculated using bone-length and length-weight regressions. Sample sizes (n) calculated using this technique (with percentage) are provided for each prey family recovered from lemon shark stomachs in the North Sound (NS) and South Bimini (SB) nurseries at Bimini, Bahamas

\begin{tabular}{|c|c|c|c|c|c|c|}
\hline & \multicolumn{2}{|c|}{ Weight (g) } & \multicolumn{2}{|c|}{ North Sound } & \multicolumn{2}{|c|}{ South Bimini } \\
\hline & NS & SB & $\mathrm{n}$ & $\%$ & $\mathrm{n}$ & $\%$ \\
\hline \multicolumn{7}{|l|}{ Teleosts } \\
\hline Atherinidae (silversides) & 28.60 & 21.60 & 17 & 63 & 9 & 60 \\
\hline Balistidae (triggerfish and filefishes) & 91.99 & 36.41 & 13 & 81 & 1 & 100 \\
\hline Batrachoididae (toadfishes) & 93.58 & 45.85 & 9 & 90 & 7 & 70 \\
\hline Belonidae (needlefishes) & 83.04 & 179.56 & 4 & 50 & 3 & 100 \\
\hline Bothidae (lefteye flounders) & 6.01 & - & 1 & 100 & & \\
\hline Carangidae (jacks) & 53.24 & 16.21 & 4 & 80 & 2 & 100 \\
\hline Cyprinodontidae (killifishes) & 1.62 & - & 3 & 75 & & \\
\hline Gerreidae (mojarras) & 6820.49 & 1965.26 & 86 & 72 & 36 & 84 \\
\hline Gobiidae (gobies) & 32.72 & 0.77 & 5 & 100 & 1 & 100 \\
\hline Haemulidae (grunts) & 329.33 & 399.48 & 9 & 69 & 8 & 73 \\
\hline Hemiramphidae (halfbeaks) & 2.03 & - & 1 & 50 & & \\
\hline Labridae (wrasses) & 1.74 & - & 1 & 50 & & \\
\hline Lutjanidae (snappers) & 800.55 & 289.37 & 13 & 87 & 9 & 90 \\
\hline Ophichthidae (snake eels) & 4.97 & - & 3 & 60 & & \\
\hline Pomacentridae (damselfishes) & - & 11.76 & & & 2 & 100 \\
\hline Scaridae (parrotfishes) & 1238.02 & 1232.69 & 22 & 63 & 43 & 86 \\
\hline Soleidae (soles) & - & 0.17 & & & 1 & 100 \\
\hline Sparidae (porgies) & 0.90 & 17.88 & 1 & 100 & 1 & 100 \\
\hline Sphyraenidae (barracudas) & 1081.48 & 231.39 & 15 & 56 & 6 & 60 \\
\hline Synodontidae (lizardfishes) & 51.92 & - & 1 & 100 & & \\
\hline \multicolumn{7}{|l|}{ Crustaceans } \\
\hline Gonodactylidae (mantis shrimps) & 17.70 & 1.95 & 3 & 100 & 1 & 50 \\
\hline Penaeidae (penaeid shrimps) & 77.15 & 15.55 & 24 & 60 & 5 & 83 \\
\hline Portunidae (swimming crabs) & 886.66 & 79.87 & 24 & 42 & 3 & 50 \\
\hline Pseudosquillidae (mantis shrimps) & 14.97 & 6.01 & 4 & 67 & 2 & 100 \\
\hline
\end{tabular}

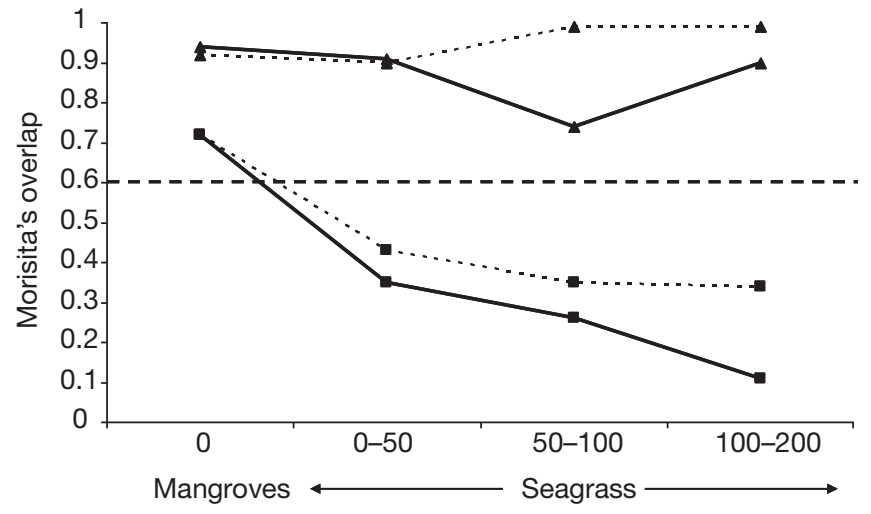

Fig. 2. Negaprion brevirostris. Overlap between prey families found in the diet and environment: North Sound $(\mathbf{\Lambda})$, South Bimini (घ), wet season (short dashed line) and dry season (solid line), with increasing distance from the mangrove fringe (in $\mathrm{m}$ ). Overlap was calculated with the simplified Morisita's index using the index of relative importance values expressed as a percentage for each prey family. Morisita's values were significant if $>0.60$ (represented by dashed line), and as a dimensionless number have no error bars and mangrove communities demonstrates the importance of mangroves to juvenile lemon sharks and their prey. Overlap was slightly less during the dry season in both nurseries (Fig. 2), most likely due to lower abundances of mojarra (see Table 2).

\section{Prey size selection}

Juvenile lemon sharks positively selected for size of teleosts and crustaceans, with prey sizes in the diet significantly larger than sizes in the environment in both North Sound and South Bimini nurseries (MannWhitney $U$-test, $\mathrm{p}<0.05$; Fig. 3). Juvenile lemon sharks consumed disproportionally less of the smallest and largest prey found in the environment, positively selecting for intermediate sizes (Fig. 3). Of the major prey items found in the diet, all but barracuda and toadfish were positively selected for size (Fig. 4). Lemon sharks demonstrated positive selection for size of mojarra, parrotfish, snappers and grunts, as well as penaeid shrimps and swimming crabs (Fig. 4). Analyses of selection by species revealed no size selection for yellowfin mojarra in either nursery (Mann-Whitney $U$-test, p > 0.1). 

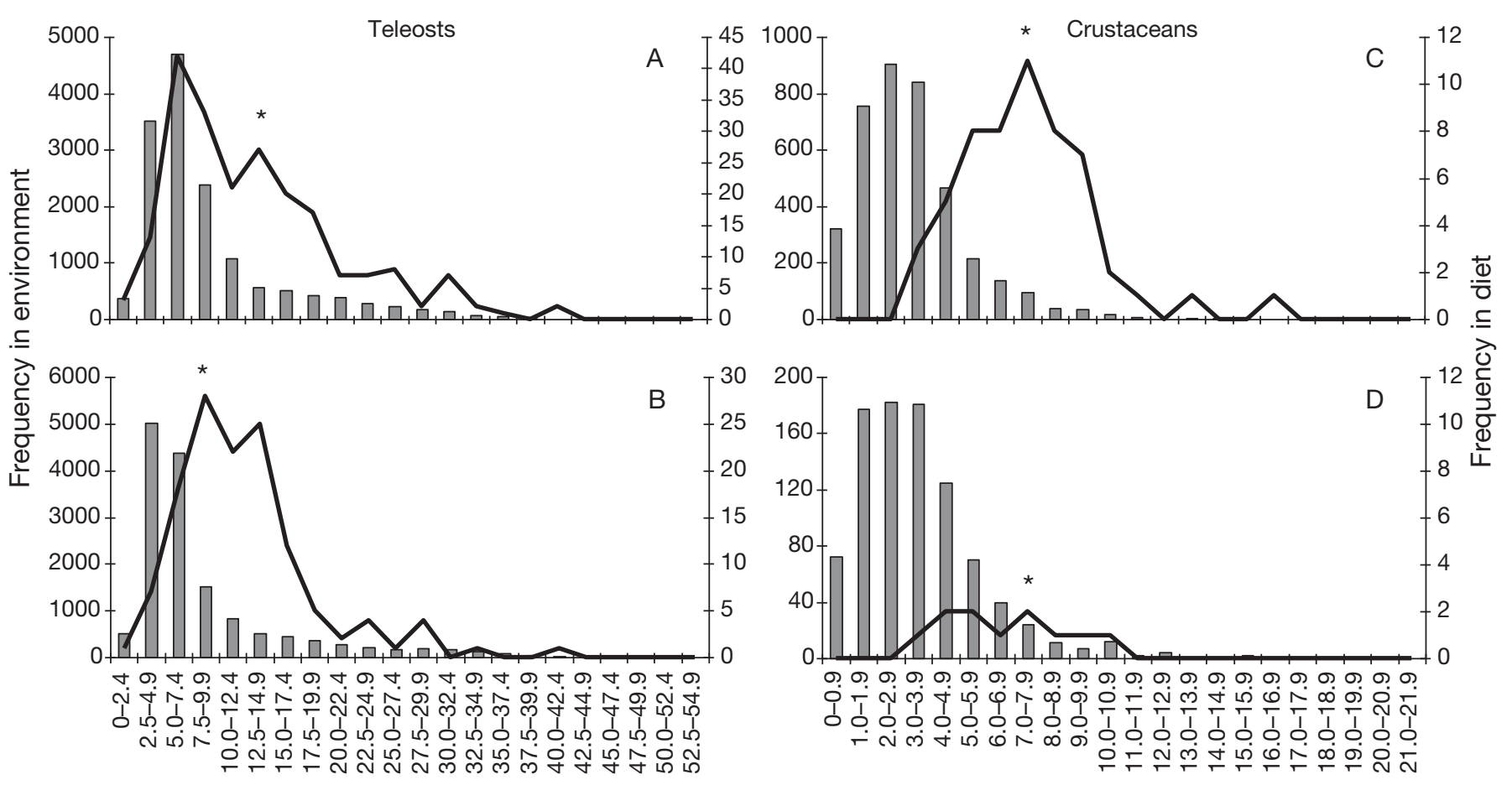

Prey size $(\mathrm{cm})$

Fig. 3. Total length-frequency histogram of teleosts and crustaceans caught in the environment (bars, $\mathrm{n}=22617$ ) and in the diet of juvenile lemon sharks Negaprion brevirostris (lines) in the North Sound (A and C, $\mathrm{n}=212$ ) and off South Bimini (B and D, $\mathrm{n}=$ 131). Prey size is total length in teleosts and shrimps and carapace width in crabs. Asterisks indicate significant differences in median sizes (Mann-Witney $U$-test, $\mathrm{p}<0.05$ )

\section{DISCUSSION}

Results from the present study quantitatively demonstrate that juvenile lemon sharks Negaprion brevirostris do not feed randomly on available prey, but may exhibit preferences according to both prey species and prey size. Juvenile lemon sharks also respond to differences in prey abundance between locations; with stronger preferences when prey communities were more abundant and diverse, as was the case off South Bimini. While this significantly increases our knowledge of the feeding behaviour of this species, using the lemon shark as a model species also increases our understanding of foraging in sharks as a whole, and challenges the paradigm of all sharks being asynchronous opportunistic predators.

Analysis of stomach contents confirmed the findings of earlier studies (Springer 1950, Schmidt 1986, Cortés \& Gruber 1990), with lemon sharks being predominantly piscivorous (93 to $99 \%$ IRI). The larger sample size in the present study $(\mathrm{n}=396)$ in comparison to earlier studies $(\mathrm{n}=18$ off Florida [Schmidt 1986]; $\mathrm{n}=78$ in Bimini and the Florida Keys and $\mathrm{n}=$ 86 in the Florida Keys [Cortés \& Gruber 1990]) led to the expected identification of a wider range of prey in the diet of juvenile lemon sharks (51 species from 31 families). The present study was the first to analyse seasonal differences in lemon shark diet, although no significant variation was found. Wetherbee et al. (1990) attributed the lack of seasonal variation in the diet of juvenile sharks to limited prey abundance within the nursery, while Lyle (1983) partly attributed seasonal changes in the diet of lesser-spotted dogfish Scyliorhinus canicula to shifts in prey availability. However, in the present study, lack of seasonal variation in diet could be attributed to a degree of feeding preference.

Yellowfin mojarra were the major prey irrespective of season, shark gender, or abundance in the environment, revealing that lemon sharks can be specialised piscivores. Previous studies of juvenile lemon shark diet reported snappers to be the most important prey in Bimini (Cortés \& Gruber 1990), while toadfish and porgies were important in the Florida Keys (Schmidt 1986, Cortés \& Gruber 1990). These differences in diet are most likely due to spatial and temporal variations in prey communities at different locations (Wetherbee et al. 1990), or anthropogenic-related habitat degradation. Dietary data indicated plasticity in the feeding of lemon sharks, which occasionally included benthic 
organisms such as sand eels, lugworms, crabs and the stingray Dasyatis americanus. The occurrence of stingray in the diet of juvenile lemon sharks at Bimini suggests group feeding behaviour such as communal scavenging or pack hunting, with all the sharks that had consumed stingray caught within an hour of each other with pieces of the same individual ray in their stomachs. Subsequently, stingray was omitted from the determination of prey preference, as were sand eels and lugworms, which were not targeted by the community sampling methodology.

Lemon sharks demonstrated a degree of prey preference in both nurseries at Bimini, with similar spatial and temporal trends in preference identified by chisquared residuals. Prey preference was determined using abundance, \%IRI values and original weight of ingested prey. Prey preference is typically calculated using abundance data, with many studies lacking the
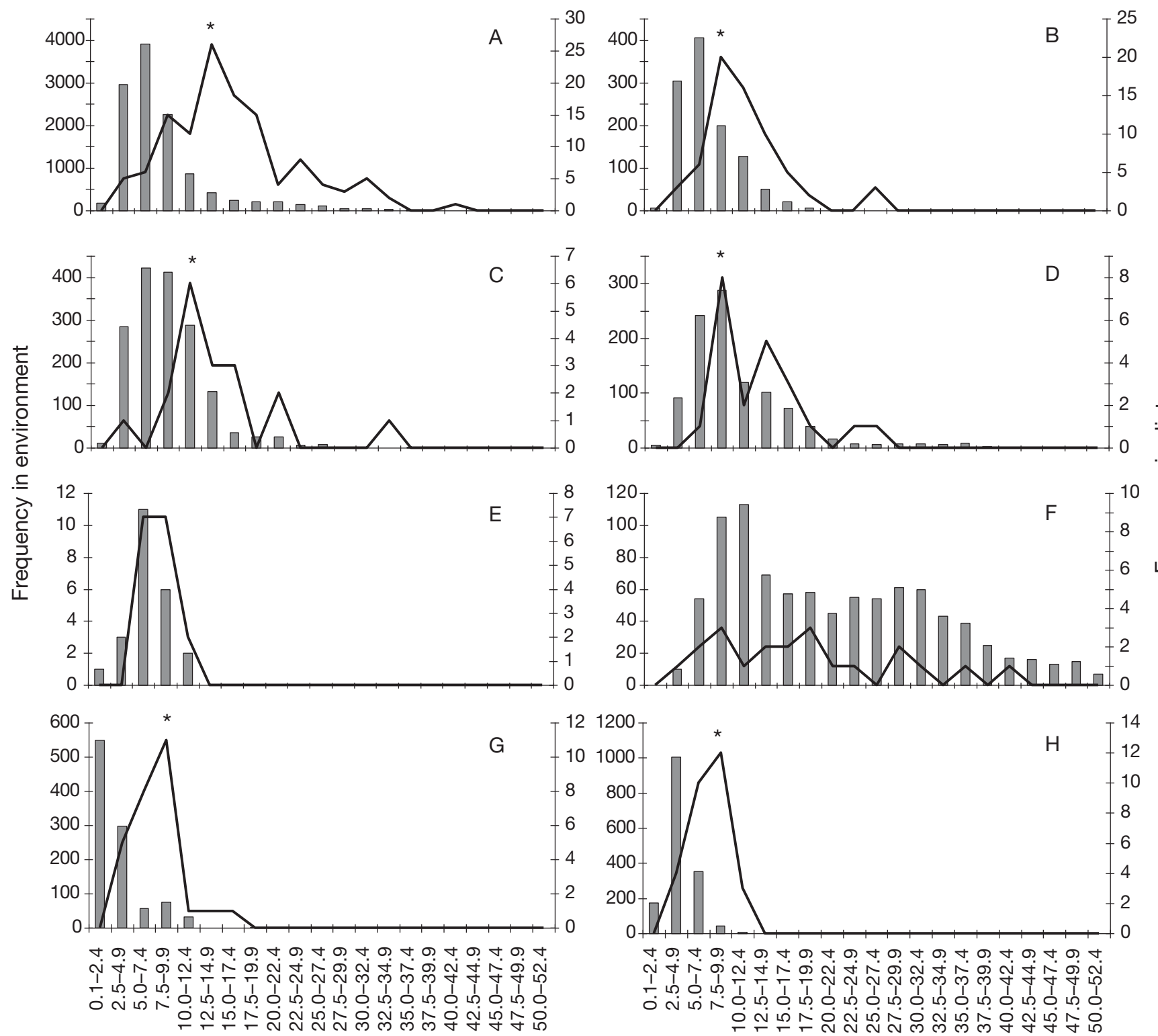

Prey size (cm)

Fig. 4. Size-frequency histograms of prey in the environment (bars) and in the diet of juvenile lemon sharks Negaprion brevirostris (lines) at Bimini, Bahamas. (A) Mojarra, Gerreidae ( $\mathrm{n}=11660$ measurements from the environment, 124 from shark stomachs); (B) parrotfish, Scaridae $(\mathrm{n}=1125,65)$; (C) grunt, Haemulidae $(\mathrm{n}=1658,18) ;(\mathrm{D})$ snapper, Lutjanidae $(\mathrm{n}=1026,22)$; $(\mathrm{E})$ toadfish, Batrachoididae $(\mathrm{n}=23,16)$; $(\mathrm{F})$ barracuda, Sphyraenidae $(\mathrm{n}=916,21) ;(\mathrm{G})$ swimming crab, Portunidae $(\mathrm{n}=1017,27) ;(\mathrm{H})$ shrimp, Penaeidae $(\mathrm{n}=1582,29)$. Prey size is total length in teleosts and shrimps and carapace width in crabs. Asterisks indicate significant differences between median sizes in environment and lemon shark diet (Mann-Whitney $U$-test, $p<0.05$ ) 
resolution to determine pre-digestion weights of prey from bones recovered from a predator's stomach. Values of \%IRI provide a good compound index of abundance, weight and occurrence of prey in the diet, allowing a clearer interpretation of a predators' preference for different prey without bias from highly abundant small prey in the diet. However, pre-digestion weights of prey closely relate to the energetic intake of a predator and, when available, are the best values to use for determining prey preference. Although mojarra were the main prey item, prey preference estimates using original weight of ingested prey suggest the following preference hierarchy in juvenile lemon sharks: parrotfish $>$ mojarra $>$ toadfish $>$ filefish $>$ grunts $>$ barracuda.

Regardless of the methodology used to determine prey preference, these analyses suggest lemon sharks in the North Sound fed more opportunistically on mojarra than sharks off South Bimini, because mojarra were abundant in both the diet and the environment. Prey preference needs to be confirmed at sites with different prey abundances (Wetherbee et al. 1990), and the South Bimini nursery serves as this comparative site with mojarra at lower densities. Sharks in this nursery continued to consume large numbers of mojarra despite the lower abundance of mojarra in the environment, revealing the true high degree of preference for mojarra by lemon sharks. Predators can affect prey directly by consumption, indirectly by altering the behaviour of prey (e.g. intimidation in marine mammals; Wirsing et al. 2007), and can, through selective foraging, influence population structure and composition (Kitchell et al. 1994). While the effect of prey preference in juvenile lemon sharks requires further attention, the reasons for the preference exhibited may involve predator hunting ability and experience, as well as prey vulnerability.

Lemon sharks fed with greater selectivity upon slower, easily captured species more vulnerable to predation. This supports findings in species such as the tiger shark, which predominantly feed on slow benthic animals and air-breathing marine vertebrates (Simpfendorfer et al. 2001, Heithaus et al. 2002). In the lemon shark this is illustrated by preference for toadfish, a relatively sedentary animal that is also vulnerable to predation due to their low-frequency vocalizations (Cortés \& Gruber 1990), and for mojarras, which are vulnerable due to their foraging behaviour of hovering stationary above the substrate while foraging (Cyrus \& Blaber 1982). This is further supported by the high preference of lemon sharks for juvenile parrotfish and filefish, which appear to rely upon camouflage rather than an escape response to avoid predation (S. Newman pers. obs.). However, in the present study the low abundance of parrotfish and filefish in the diet of juvenile lemon sharks is probably explained by the lack of larger individuals in the nursery, which have probably migrated to nearby reefs and are therefore unavailable for consumption. Conversely, snappers had a lower than expected occurrence in the diet of lemon sharks (5.3 to $6.9 \%$ O, 0.77 to $1.35 \%$ IRI; see Table 1 ) than previously reported (10.2 to $10.9 \%$ O; Cortés \& Gruber 1990). Snappers may be less vulnerable to predation due to their high motility and tendency to refuge in the mangroves at Bimini (Newman et al. 2007). This is further supported by the greater preference exhibited by lemon sharks for snapper in the North Sound, where mangrove cover is less complex (dwarf mangroves in comparison to dense fringing mangroves off South Bimini), suggesting that a threshold level of habitat complexity may influence foraging success in lemon sharks, as has been demonstrated in freshwater teleosts (e.g. Gotceitas \& Colgan 1989). This highlights the importance of the combined effects of fish behaviour and habitat in driving some aspects of prey preference.

Measures of overlap between lemon shark diet and prey communities were greatest for mangroves, demonstrating their importance to lemon sharks and their prey. High overlap between shark diet and prey communities at all distances from the shore observed in the North Sound supports the opportunistic feeding exhibited by lemon sharks in this nursery. While nurseries are broadly classified as essential fish habitat for sharks (Heithaus 2007), correlating shark diet with prey communities can provide insight into critical habitats within nurseries such as the mangroves at Bimini. Mangroves may be a vital link in the food chain that lemon sharks indirectly rely upon in this system, and, although further research is required to demonstrate this, the protection of mangroves should be a priority to ensure the conservation of lemon sharks in these nurseries.

The present study is the first quantification of prey size selection in lemon sharks, revealing positive size selection for all prey families except for toadfish and barracuda. Sampling of prey in the environment using block nets, seines and trawls, resulted in the capture of very small and very large prey and provided a representative dataset for accurate comparison with shark diet. Lemon sharks demonstrated a preference for intermediate-sized teleosts and crustaceans, suggesting a trade off between capture probability and profitability (energetic intake). The mean size of prey in the diet of juvenile lemon sharks at Bimini was $12.4 \pm 0.4 \mathrm{~cm}$ $\mathrm{TL}$, although this mean was strongly influenced by the high frequency of large mojarra in the diet. Only barracuda ( $69 \%$ of measured fish) and yellowfin mojarra $(63 \%)$ were present at this size or larger in any significant numbers in the environment, while, in contrast, 
few parrotfish $(7 \%)$ or portunid crabs $(0.4 \%)$ and no toadfish or penaeid shrimp were present at this size or larger. Prey size selection in lemon sharks is therefore ecologically complex, with maximum size limited by availability of prey sizes in the environment, predator hunting ability and the ability of prey to avoid capture.

The taxonomic analysis also revealed the level of species resolution in prey size selection by the sharks. Analysis to species level for yellowfin mojarra revealed they were consumed by lemon sharks in proportion to prey sizes in the environment. Juvenile lemon sharks probably do not distinguish between species of mojarra, but analysis to species level excluded highly abundant small mojarra from the genus Eucinostomus (e.g. slender mojarra E. jonesii, silver jenny E. gula and flagfin mojarra E. melanopterus). Yellowfin mojarra were therefore probably the major dietary item of juvenile lemon sharks, not only because of their conspicuousness and ease of capture, but also because of abundant favourable (larger) sizes in the environment.

Foraging in juvenile lemon sharks can be thought of in terms of the diet-width model, which suggests that a predator 'encounters prey in proportion to their abundances in the environment and then makes a choice to either catch the prey or continue searching' (MacArthur \& Pianka 1966). The interval between feeding in lemon sharks is relatively long (between 33 and $47 \mathrm{~h}$; Cortés \& Gruber 1990), supporting this model. If a predator is too specialised, then it will spend most of its time (and therefore energy) searching for prey, but if it is too generalised then it will pursue a lot of unprofitable prey. Lemon sharks were more selective off South Bimini, where prey were more abundant, conforming to optimal foraging theory, which suggests that predators become progressively more selective as prey numbers increase (Krebs \& McCleary 1984). Predators may become less selective in areas where prey are scarce due to increased hunger resulting in opportunistic feeding, e.g. in marine invertebrates (Landenberger 1968) and teleosts (Werner \& Hall 1974, Pyke 1979). This may account for the greater degree of opportunistic feeding by lemon sharks in the North Sound, which, in combination with eurythermal and euryhaline conditions, could be the principal reason for the lower somatic growth reported in this nursery in comparison to elsewhere in the Gulf of Mexico/Caribbean region (Barker et al. 2005).

In summary, the present study quantitatively shows that lemon sharks do not feed randomly and can demonstrate a high degree of prey preference and size selection when environmental conditions are favourable. This highlights the need to quantitatively compare shark diet with prey communities at different densities, rather than make statements on the prey preference (or lack of) exhibited by a species of shark based solely on the species diversity and composition of dietary data. Lemon sharks were more opportunistic foragers in the less environmentally favourable North Sound nursery, where prey communities were less dense or diverse. This has broader implications for the feeding of sharks that inhabit areas of low prey density (e.g. pelagic species), which may forage more opportunistically in order to survive.

Acknowledgements. The present study was supported in part by the Florida Department of Education (Grant 874-9703000001; S.H.G.), a studentship from the University of Plymouth (S.P.N.), PADI project AWARE (S.P.N.), the Bimini Biological Field Station and its supporters, the National Fish and Wildlife Foundation, the Hoover Foundation, B. Newman, N. \& E. Phillips, T. \& S. Daniels and T. \& T. Fujino. Many thanks to the staff and volunteers of the Bimini Biological Field Station, with special thanks to K. Parsons, D. McElroy, C. Hofmann, B. Franks, S. Kessel, J. Brady, M. Calosso, D. Chagaris, T. DiGirolamo and A. Grant. We thank the anonymous reviewers of this manuscript for their constructive comments. This work was carried out in collaboration with the Bimini Biological Field Station, Bahamas, under University of Miami's Bahamian research permit (MAF/LIA/22). We also thank the Commonwealth of the Bahamas, Department of Fisheries (M. Braynen, Director) for issuing permits to allow us to work in the controlled waters of the Commonwealth of the Bahamas.

\section{LITERATURE CITED}

Baremore IE, Murie DJ, Carlson JK (2008) Prey selection by the Atlantic angel shark Squatina dumeril in the northeastern Gulf of Mexico. Bull Mar Sci 82:297-313

Barker MJ, Gruber SH, Newman SP, Schluessel V (2005) Spatial and temporal variation in growth of nursery-bound juvenile lemon sharks (Negaprion brevirostris): a comparison of two novel age-assigning techniques. Environ Biol Fishes 72:343-355

Bethea DM, Hale L, Carlson JK, Cortés E, Manire CA, Gelsleichter J (2007) Geographic and ontogenetic variation in the diet and daily ration of the bonnethead shark, Sphyrna tiburo, from the eastern Gulf of Mexico. Mar Biol 152: 1009-1020

Clarke TA (1971) The ecology of the scalloped hammerhead, Sphyrna lewini, in Hawaii. Pac Sci 25:133-144

Cock MJW (1978) The assessment of preference. J Anim Ecol 47:805-816

Cortés E (1997) A critical review of methods of studying fish feeding based on analysis of stomach contents: application to elasmobranch fishes. Can J Fish Aquat Sci 54:726-738

> Cortés E, Gruber SH (1990) Diet, feeding habits and estimates of daily ration of young lemon sharks, Negaprion brevirostris. Copeia 1990:204-218

Cyrus DP, Blaber SJM (1982) Mouthpart structure and function and the feeding mechanisms of Gerres (Teleostei). S Afr J Zool 17:117-121

Feldheim KA, Gruber SH, Ashley MV (2002) The breeding biology of lemon sharks at a tropical nursery lagoon. Proc Biol Sci 269:1655-1661

Gotceitas V, Colgan P (1989) Predator foraging success and habitat complexity: quantitative test of the threshold hypothesis. Oecologia 80:158-166

Gotelli NJ, Entsminger GL (2009) EcoSim: null models software for ecology, Vers 7. Acquired Intelligence 
Inc. \& Kesey-Bear, Jericho, VT. Available at: http:// garyentsminger.com/ecosim.htm

Heithaus MR (2007) Nursery areas as essential shark habitats: a theoretical perspective. In: McCandless CT, Kohler NE, Pratt HL Jr (eds) Shark nursery grounds of the Gulf of Mexico and the east coast waters of the United States. Symposium 50, American Fisheries Society, Bethesda, MD, p 3-13

Heithaus MR, Dill LM, Marshall GJ, Buhleier B (2002) Habitat use and foraging behavior of tiger sharks (Galeocerdo cuvier) in a seagrass ecosystem. Mar Biol 140:237-248

Horn HS (1966) Measurement of 'overlap' in comparative ecological studies. Am Nat 100:419-424

Hyslop EJ (1980) Stomach content analysis-a review of methods and their application. J Fish Biol 17:411-429

Johnson DH (1980) The comparison of usage and availability measurements for evaluating resources preference. Ecology 61:65-71

Kitchell JF, Eby LA, He X, Schindler DE, Wright RA (1994) Predator-prey dynamics in an ecosystem context. J Fish Biol 45:209-226

Krebs CJ (1999) Ecological methodology, 2nd edn. Benjamin Cummings, Menlo Park, CA

Krebs JR, McCleary RH (1984) Optimisation and behavioural ecology. In: Krebs JR, Davies NB (eds) Behavioural ecology, an evolutionary synthesis. Sinauer, Sunderland, MA, p 91-121

Landenberger DE (1968) Studies on selective feeding in the Pacific starfish Pisaster in southern California. Ecology 49: 1062-1075

Lechowicz MJ (1982) The sampling characteristics of electivity indices. Oecologia 52:22-30

Lindberg DR, Warheit KI, Estes JA (1987) Prey preference and seasonal predation by oystercatchers on limpets at San Nicholas Island, California, USA. Mar Ecol Prog Ser 39:105-113

Lopez-Mendilaharsu M, Gardner SC, Riosmena-Rodriguez R, Seminoff JA (2008) Diet selection by immature green turtles (Chelonia mydas) at Bahia Magdalena foraging ground in the Pacific coast of the Baja California peninsula, Mexico. J Mar Biol Assoc UK 88:641-647

Lukoschek V, McCormick MI (2001) Ontogeny of diet changes in a tropical benthic carnivorous fish, Parupeneus barberinus (Mullidae): relationship between foraging behaviour, habitat use, jaw size, and prey selection. Mar Biol 138:1099-1113

Lyle JM (1983) Food and feeding habits of the lesser spotted dogfish, Scyliorhinus canicula (L.), in Isle of Man waters. J Fish Biol 23:725-737

MacArthur RH, Pianka ER (1966) On optimal use of a patchy environment. Am Nat 100:603-609

Manley BFJ, McDonale LL, Thomas D (1993) Resource selection by animals. Chapman \& Hall, London

Medved RJ, Stillwell CE, Casey JG (1985) Stomach contents of young sandbar sharks, Carcharhinus plumbeus, in Chincoteague Bay, Virginia. Fish Bull 83:395-402

Morrissey JF, Gruber SH (1993a) Home range of juvenile lemon sharks, Negaprion brevirostris. Copeia 1993: 425-434

Morrissey JF, Gruber SH (1993b) Habitat selection by juvenile lemon sharks, Negaprion brevirostris. Environ Biol Fishes 38:311-319

Newell ND, Imbrie J (1955) Biogeological reconnaissance in the Bimini area, Great Bahama Bank. Trans N Y Acad Sci $2: 3-14$

Newman RM, Waters TF (1984) Size-selective predation on Gammarus pseudolimnaeus by trout and sculpins. Ecology 65:1535-1545

Editorial responsibility: Yves Cherel,

Villiers-en-Bois, France
Newman SP, Handy RD, Gruber SH (2007) Spatial and temporal variations in mangrove and seagrass faunal communities at Bimini, Bahamas. Bull Mar Sci 80:529-553

NMFS (National Marine Fisheries Service) (2001) Final United States national plan of action for the conservation and management of sharks. February, 2001. NMFS, Silver Springs, MD

Pearre S (1982) Estimating prey preference by predators, uses of various indices, and a proposal of another based on $\chi^{2}$. Can J Fish Aquat Sci 39:914-923

Pinkas LM, Oliphant S, Iverson ILK (1971) Food habits of albacore, bluefin tuna, and bonito in California waters. Calif Fish Game 152:1-105

Pyke GH (1979) Optimal foraging in fish. In: Clepper H (ed) Predator-prey systems in fisheries management. Sport Fishing Institute, Washington, DC, p 199-202

Schmidt TW (1986) Food of young juvenile lemon sharks, Negaprion brevirostris (Poey), near Sandy Key, western Florida Bay. Fla Sci 49:7-10

> Schurdak ME, Gruber SH (1989) Gastric evacuation of the lemon shark, Negaprion brevirostris (Poey) under controlled conditions. Exp Biol 48:77-82

Simpfendorfer CA, Goodreid AB, McAuley RB (2001) Size, sex and geographic variation in the diet of the tiger shark, Galeocerdo cuvier. Environ Biol Fishes 61:37-46

Springer S (1950) Natural history notes on the lemon shark, Negaprion brevirostris. Tex J Sci 3:349-357

Springer S (1960) Natural history of the sandbar shark, Eulamia milberti. Fish Bull 61:1-38

Stillwell CE, Kohler NE (1982) Food, feeding habits, and estimates of daily ration of the shortfin mako (Isurus oxyrinchus) in the northwest Atlantic. Can J Fish Aquat Sci 39:407-414

Talent LG (1976) Food habits of the leopard shark, Triakis semifasciata, in Elkhorn Slough, Monterey Bay, California. Calif Fish Game 62:286-298

Tricas TC (1979) Relationships of the blue shark, Prionace glauca, and its prey species near Santa Catalina Island, Calif. Fish Bull 77:175-182

Tricas TC, McCosker JE (1984) Predatory behavior of the white shark (Carcharodon carcharias), with notes on its biology. Proc Calif Acad Sci 43:221-238

Voss GL, Voss NA (1960) An ecological survey of the marine invertebrates of Bimini, Bahamas, with a consideration of the zoogeographical relationships. Bull Mar Sci Gulf Caribb 10:96-116

Wathne JA, Haug T, Lydersen C (2000) Prey preference and niche overlap of ringed seals Phoca hispida and harp seals P. groenlandica in the Barents Sea. Mar Ecol Prog Ser 194: 233-239

Werner EE, Hall DJ (1974) Optimal foraging and the size selection of prey by the bluegill sunfish (Lepomis macrochirus). Ecology 55:1042-1052

Wetherbee BM, Gruber SH, Cortés E (1990) Diet, feeding habits, digestion and consumption in sharks, with special reference to the lemon shark, Negaprion brevirostris. In: Pratt HL Jr, Gruber SH, Tauriuchi T (eds) Elasmobranchs as living resources, advances in the biology, ecology, systematics and the states of the fisheries. NOAA Tech Rep, NMFS, p 29-47

> Wirsing AJ, Heithaus MR, Frid A, Dill LM (2007) Seascapes of fear: evaluating sublethal predator effects experienced and generated by marine mammals. Mar Mamm Sci 24:1-15

Zaret TM, Rand AS (1971) Competition in tropical stream fishes, support for the competitive exclusion principal. Ecology 52:336-342 